\title{
Erratum to: The evolutionary context for a self-nonself discrimination
}

\section{Melvin Cohn}

Published online: 31 July 2010

(C) Springer Basel AG 2010

Erratum to: Cell Mol Life Sci

DOI 10.1007/s00018-010-0438-z

It has come to our attention that in Fig. 1a headline is missing. It has now been incorporated into Fig. 1.

A The fork-in-the-road model

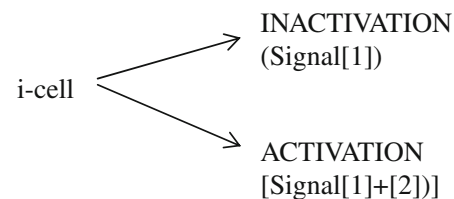

B The sequential model

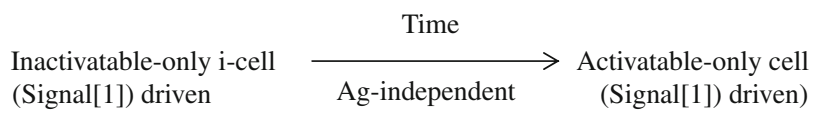

Fig. 1 The two configurations of the inactivation-activation decision

The online version of the original article can be found under doi:10.1007/s00018-010-0438-z.

M. Cohn ( $\square)$

Conceptual Immunology Group,

The Salk Institute for Biological Studies,

10010 North Torrey Pines Road, La Jolla, CA 92037, USA

e-mail: cohn@salk.edu 